\title{
PARA UMA REPRESENTAÇÃO NÃO PATRIARCAL DO FEMININO
}

\author{
Rafael Kalaf Cossi \\ Doutor em Psicologia Clínica pela USP
}

\section{Publicação}

Irigaray, L. (2017). Este sexo que não é só um sexo: sexualidade e status social da mulher. (C. Prada, Trans.). São Paulo: Editora Senac. (Trabalho original publicado em 1977)

\section{RESENHA}

O feminismo pode ser didaticamente dividido em três grandes ondas: a primeira, intitulada "feminismo da igualdade" e que foi até meados do século XX, lutava por igualdade social e política com relação aos homens - é neste período que os trabalhos de Karen Horney e Helene Deutch ganham destaque dentro do universo psicanalítico dos anos 1920, ao contestar o que consideravam ser as bases patriarcalistas inerentes aos desenvolvimentos freudianos do Édipo e ao lugar inferiorizado concedido à mulher em sua obra. A segunda onda feminista vige até a década 1980, o "feminismo das diferenças". Desta vez a estratégia é focar a mulher em si mesma e exaltar suas especificidades - as peculiaridades de seu corpo são acentuadas, a refletir na esfera discursiva, jurídica, política e econômica. Por volta dos anos 1990, ganha profusão a terceira onda, que passa a contestar o mecanismo que promove a legitimação de certas manifestações da sexualidade, e o banimento daquelas que não correspondem à norma. A teoria queer adquire notoriedade e a própria noção de identidade é posta em xeque. Butler, bell hooks, De Lauretis e, mais recentemente, Preciado, são grandes nomes deste momento.

No trânsito da segunda para a terceira onda, um desmembramento se deu dentro do feminismo psicanalítico - se sua vertente anglo-saxã, sustentada na teoria das relações de objeto, pretendia abalar o poder patriarcal através de reconfigurações da família, das relações de trabalho e dos alicerces ideológicos dos gêneros, a ala francesa dava relevo à linguagem e a sua repercussão em âmbito social - as engrenagens discursivas patriarcalistas que impediam 0 reposicionamento da mulher nesta esfera deveriam ser desveladas e derrocadas. Derrida é autor privilegiado nesta empreitada, ao fornecer a noção de desconstrução que fundamenta uma prática de desmonte dos princípios e postulados dos textos.

É neste período que surge Luce Irigaray (1932), uma das protagonistas do feminismo psicanalítico francês e que, junto de Hélène Cixous e Catherine Clément, esboçou o "Movimento da escrita feminina". Em seu trabalho, dialoga 
com um vasto campo: da filosofia pré-socrática à pós-estruturalistas, da psicanálise de Freud a Lacan, dentre outros.

Se participam do desfalque causado à mulher conjunturas econômicas, sociais, morais e legais, Irigaray dá enfoque ao processo de dominação masculina retratado no plano da linguagem, e que acaba por entrar em jogo na edificação de nossa ordem social de cunho patriarcal. O homem assume a economia do Mesmo e o pensamento simétrico, nos termos de Irigaray, regido pela razão, proporção, previsão, clareza e coerência. À mulher, o avesso: irreflexão, desmedida, insensatez, mistério e desnexo. Ao homem concerne o nobre mundo das ideias e as rédeas da zona discursiva, ao passo que o terreno dela é o corpo indócil que compete à natureza. Mas Irigaray sustenta que a ideia de uma predeterminação "ahistórica" deste cenário é fruto de uma estratégia política em vias de perpetuar o poder na mão dos homens: destitui-se a mulher do acesso a uma dignidade ontológica em seus próprios termos - ela é o que o homem diz que ela é e o que deve fazer; é sua verão negativa, à medida que funciona como a exclusão constitutiva da instituição varonil. Dai Irigaray apontar que nossa cultura só concebe um sexo, o masculino - a mulher é o outro sem integridade, o sexo que não é um.

Segundo a autora, a psicanálise seria herdeira desta quimera ideológica e teria produzido acriticamente seu arcabouço teórico sob tal perspectiva - disso decorre todo seu esforço em denunciar um suposto ranço patriarcal entranhado nos desenvolvimentos de Freud e Lacan. Se Ihe deu notoriedade no meio feminista, seu primeiro livro, Speculum de l'autre femme, de 1974, levou-a à expulsão da Escola Freudiana de Paris e à interrupção de sua carreira de docente em Vincennes.

No enredo derrideano, o falogocentrismo teria formatado a metafísica do pensamento ocidental, a reverberar tanto no discurso filosófico quanto no psicanalítico. Este sistema parte de uma lógica da presença que habilita a confrontação de dois elementos substancializados radicalmente opostos, a partir do que a diferença seria empreendida, tal como se nota nos pares yin/yang e mente/corpo. Esse procedimento hierárquico que impõe a submissão de um dos termos pelo outro agiria também no interior no patriarcado, com invenção do binário homem/mulher. Ele é identificado ao significante fálico, significante extraordinário e único ordenador da sexualidade; ela ao subalterno desregrado se elidida da linguagem, serve de embrião e pilar que alicerça esta estrutura capitaneada pelo Pai.

Sob os mesmos critérios, a mulher é equiparada ao homem: inveja do pênis, superego manco, restrito senso de justiça são considerações freudianas atribuídas a ela, quando abordada em referência a ele. "Não toda", "A mulher não existe" o lacanismo renovaria a postura freudiana de tomar a mulher como uma versão menor do homem? Neste sentido, ela só seria perscrutada em menção a ele, não em sua heterogeneidade. Dai a provocação: haveria espaço dentro da psicanálise para que a mulher fosse tratada em sua particularidade, sem o recurso da 
comparação com o homem ou através do panorama fantasístico que ele fabrica? À medida que ela pudesse falar de si nos seus próprios termos, seria escancarada a ficcionalidade do status de objeto-enigma que lhe é designado, cujos sintomas intrigantes são como hieróglifos a serem decifrados pelo saber masculino. $O$ que se revelaria para além das parcas possibilidades fálicas que o homem Ihe autoriza, no caso, a mascarada e a maternagem?

Falo, Nome-do-Pai, lei paterna são, para Irigaray, conceitos nucleares da psicanálise confeccionados estritamente aos moldes masculinos, a partir dos quais a diferença sexual seria contemplada desprezando os aspectos históricos que participam de seu entendimento. Nesta manobra, a vertente de construção da diferença é ocultada, insinuando um caráter de imutabilidade imanente a tal conceito, e que, além do mais, denigre a mulher - a transcendência embutida a este operador faria dele um dado inabalável por reconfigurações sociais, legitimando a opressão e preconizando a resignação como inevitável.

A grande novidade apresentada nesta obra emblemática de Irigaray, e que funciona como um compêndio de sua ideias, se dá a ver no capítulo Così fan tutti, no qual oferece sua interpretação da sexuação de Lacan - são raras as feministas que se voltaram à vanguarda lacaniana. Para ela, o pai tomado como fundamento da lei preceitua um ideal de gozo, a partir do que o gozo feminino é prescrito como suplementar à economia fálica, fora da linguagem, inarticulável, mas não porque se trataria de seu terra de origem, mas por lhe ser vetado se articular no discurso vigente a seu modo - a experiência de gozo da mulher, o que mais poderia dizer de si, seria amordaçada.

Em seus capítulos finais, Irigaray apresenta sua tática em prol de mudanças. Se o discurso é sempre sexuado e, como numa via de mão dupla, afeta e é afetado pelos padrões sociais, para que o contexto de opressão à mulher seja abalado, há de se intervir na própria linguagem, tanto em seu conteúdo quando em seu maquinário. Incita-se a criação de novas palavras, o desarranjo das regras gramaticais, a perturbação dos códigos linguísticos - a estrutura sintática e gramatical da língua, engendrada pelo sistema falogocêntrico que favorece o patriarcado, deve desmoronar. Simbolização dos dois lábios, reparação da relação mãe-filha, incitação da mimesis são algumas das operações de guerra da proposta irigarayana. Se ao homem se associa as propriedades dos sólidos e se evidencia a centralidade monolítica de seu órgão sexual e da sua fonte de prazer, à mulher cabe o fluido e a multiplicidade de suas zonas erógenas; se o homem dá primazia à visão, Irigaray reforça a importância do toque na erótica feminina, a se autoafetar. Sobretudo, invoca uma falar próprio: falar (da) mulher.

Nesta missão, Irigaray adverte contra o risco de inflar o imaginário feminino na tentativa de constituir uma identidade final da mulher. Compor uma formação identitária se apoiando no acúmulo de traços ou adjetivos está no coração do exercício falogocêntrico que rege o patriarcado e é justamente tal sistema que se deve ter como alvo - saquear o posto de domínio dos homens só alteraria quem 
comanda, não abalaria o funcionamento do conjunto. Neste sentido, é o registro simbólico que deve estar em mira, ao qual Irigaray credita uma dinâmica que imputa a binaridade dos gêneros e dita uma relação de parentesco ideal, heterossexual, assim como elege o Édipo como um percurso universal, fixo e dicotômico que problematiza a saída feminina. Irigaray estaria então sugerindo um simbólico feminino, este que facultaria a inscrição do gozo da mulher, outorgando a viabilidade de um regime discursivo outro, para além daquele cuja lógica coordena o patriarcado?

Outra lógica, justamente aquela que comandaria a escrita feminina - escrita do gozo do corpo da mulher cuja mecânica, se transposta em âmbito social, alteraria o panorama político. Dado que o script patriarcal prevê significações fixas, agora subversões adviriam ao se operar através da hiância da linguagem.

Se o registro simbólico é determinante para a implantação da diferença, sacudir sua organização, na ótica irigarayana, permitiria vislumbrar outra maneira de concebê-la, e consequentemente, outra forma de pensar a diferença sexual, não aquela compelida por pares de opostos e dipolos hierarquizantes. Dai Irigaray entrever outra relação entre espaço e tempo, a regular um tipo de topologia não planificável que propicie a formalização de um laço entre homem e mulher que dispense o "ou um ou outro", que dê acesso a um convívio que prescinda do binarismo que provê a díade dominante-dominado.

Mas é crucial enfatizar: Irigaray é uma defensora da política da diferença sexual. Dai ser avessa à tendência do unissex e ao modismo do "sem gênero" prestigiado na atualidade. Como as modalidades de gozo são distintas e os corpos, dessemelhantes, proporcionalmente os direitos perseguidos não são os mesmo para homens e mulheres - as leis devem ser discernidas a partir do sexo. Corpo, escrita e lei a serem tomados em bloco. Para que transformações ocorram e outro espaço político seja conquistado pelas mulheres, novas representações a seu respeito devem ser tecidas, que emanem agora delas mesmas, o que só se daria com a infiltração de seu corpo e de seu tipo de gozo disrupitvo em meio discursivo.

"Este sexo que não é só um sexo" é o primeiro livro de Irigaray a ser publicado no Brasil, finalmente fazendo justiça a esta feminista que é extensamente comentada tanto em solo francófono quanto norte-americano suas elaborações são até hoje fundamentais para o mainstream dos estudos de gênero. Ao acompanharmos sua denúncia do caráter normativo de nossas instituições, inclusive a psicanalítica, também presenciamos a elaboração de seu projeto convulsionante, com a condecoração da linguagem. 
Sobre o autor:

Rafael Kalaf Cossi é psicólogo pela Universidade de São Paulo, mestre e doutor pelo Departamento de Psicologia Clínica da Universidade de São Paulo. Trabalha como psicanalista e desenvolve pesquisa na interface entre psicanálise e feminismo - estudos de gênero. É vinculado à Escola de Psicanálise do Fórum do Campo Lacaniano - SP. rkcossi@hotmail.com

Recebido em: 20/07/2017

Aceito em: 24/07/2017 